\title{
Power Quality Monitoring using Virtual Instrumentation \& LABVIEW
}

\author{
Abhishek Sur, Suman Lata Dhar
}

\begin{abstract}
This Paper principally portrays that a Power Quality Monitoring system utilizing LabVIEW is created. Because of the higher utilization of power converters and other nonlinear burdens in industry and by customers all in all, it very well may be noticed an expanding crumbling of the power frameworks voltage and current waveforms [1]. The paper 'Power Quality Monitoring using Virtual Instrumentation and LABVIEW' basically depicts the monitoring of the quality of the power generated during the process with the help of a virtual environment that is LABVIEW. Now this paper is very much simple and is based on finding the power factor along with Active, Reactive and Apparent Power.In additional to that Active/Apparent and Reactive Energies is also found out and the nature of the graph is also found out accordingly. Here we are using Current and Voltage Transformers as the basic transducers and ideal values of voltage and current is taken and the graph is plotted with respect to voltage/current and the power/energies. The nature of both the graphs is quite different in case of power it is linearly increasing with the time, whereas in case of the energies the graph is linear in nature. Also the error and accuracy is found out with a fluke data which is based on the values of fluke instruments.
\end{abstract}

Keywords: Power, Power Quality, Power Quality Monitoring (PQM), Voltage and Current Transformer, Active, Reactive, and Apparent Power, Virtual Instrumentation, LABVIEW

\section{INTRODUCTION}

$\mathrm{P}_{\text {ower quality is the arrangement of boundaries }}$ characterizing the properties of the power supply as conveyed to the client in ordinary working conditions as far as the congruity of voltage and voltage attributes". Present day electronic and power electronic gadgets are not just delicate to voltage transients; it additionally causes unsettling influences for different clients. These gadgets become the source and casualties of intensity quality issues such as voltage sag and swell. As such the term power quality is utilized to characterize the communication of electronic hardware inside the electrical climate [5][6]. Power Quality Monitoring is a multi-pronged way to deal with distinguishing, dissecting and remedying power quality issues.

Manuscript received on April 14, 2021.

Revised Manuscript received on June 09, 2021.

Manuscript published on June 30, 2021.

* Correspondence Author

Abhishek Sur*, M.Tech, Department of Electrical Electronics and Communication Engineering, School of Engineering and Technology, Sharda University, Noida (U.P), India.

Suman Lata Dhar, Assistant Professor, Department of Electrical Electronics and Communication Engineering, School of Engineering and Technology, Sharda University, Noida (U.P), India.

(c) The Authors. Published by Blue Eyes Intelligence Engineering and Sciences Publication (BEIESP). This is an open access article under the CC BY-NC-ND license (http://creativecommons.org/licenses/by-nc-nd/4.0/)
It likewise assists with recognizing the reason for power framework unsettling influences and furthermore to distinguish issue conditions before they cause interferences or aggravations, sometimes. Destinations for power quality observing are by and large arranged into two methodologies:

- Proactive methodology - It is expected to describe the framework execution and furthermore assists with comprehension and along these lines coordinate the framework execution with client needs.

- Reactive methodology - It tends to portray a particular issue and performs transient checking at explicit clients or at various loads.

It can recognize and check various kinds of wiring issues, establishing issues, exchanging load varieties, and consonant ages. Sometimes, when the helpless force quality can goes undetected, yet which brings about harming costly hardware. The non-sinusoidal current likewise causes warm and protection weight on organization gadgets, similar to transformers and feeder links [8]. Power quality eventually prompts monetary misfortunes brought about by gear personal time, expanded upkeep exercises, and more limited life times. During this article the primary target is the effects of intensity quality and the issues, Benefits alongside the observing of intensity quality is to be finished with the assistance of the virtual instrument that is LABVIEW which is an adaptable programming and that is anything but difficult to utilize [9].

\subsection{Power Quality}

Power quality includes to a decent kind of varieties inside the electrical force provided to utility clients. It can identify and check various kinds of wiring issues, establishing issues, exchanging homeless people, load varieties, and symphonious ages. Now and again, when the helpless force quality can goes undetected, yet which brings about harming costly hardware. The non-sinusoidal current additionally causes warm and protection weight on organization gadgets, similar to transformers and feeder links. During this article the principle objective is the effects of intensity quality and the issues, Benefits alongside the observing of intensity quality is to be finished.

Power quality alludes to the intensity of electrical hardware to burn-through the energy being provided there. Assortment of intensity quality issues including electrical sounds, power factor, and voltage instability and transients sway on the effectiveness of electrical gear.

This highlights various outcomes including:

$\checkmark \quad$ Higher energy utilization and expenses

$\checkmark \quad$ Higher support costs

$\checkmark \quad$ Equipment's precaution and handling.

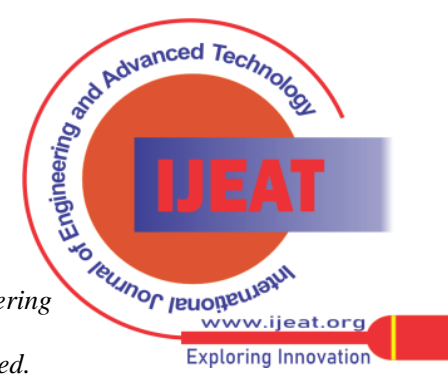


$\checkmark \quad$ Energy the executives is a pivotal thought for any business, and it's important that power quality be surveyed as a piece of any energy the board system.

\subsection{Issues of Power Quality}

Power quality issues got essential to power purchasers at all degrees of use. Sensitive gears and non-straight loads are currently more ordinary in both the financial and the business areas and in this way the home-grown climate. The use of hardware today is mainly to deal with the data. The pc business is that the greatest client of semiconductor gadgets, and customer hardware. because of the effective improvement of semiconductors, electronic framework and controls have acquired wide acknowledgment in power, data and processing innovation and gratitude to the consistent utilization of drive frameworks (rotational machines, controlling thyristor and related electronic segments) in industry and in power stations and power plants, and accordingly the had the opportunity to keep such frameworks running dependably, hardware are getting an indispensable a piece of the present modern, institutional, and business offices. Technically we can say that, A comparable kind of hardware regularly creates power supply aggravations, which in turns influence different things of unit, and are bound to get the misshaping sounds. These harmonics can make power be utilized wastefully and might be a cause of untimely breakdown which will stop creation in modern handling, will end in huge loss, preparing exercises continuously like financial exchange handling could likewise be lost, and so on [13] [14].

The major issues of power quality monitoring are as follows:-

- Voltage Sag

- Voltage Swell

- Harmonic Distortion (HD)

1.3.1 VOLTAGE SAG- It is basically defined as the decrease in the RMS (root mean square) value of the voltage, which is ranged from a half cycle to few seconds(less than 1 minute).

\section{- Causes:}

1) Faults on the transmission or distribution networks.

2) Connection of heavy loads.

\section{- Consequences:}

1) Malfunction of the microprocessor based control systems.

2) Loss of efficiency in electrical rotating machines

1.3.2 VOLTAGE SWELL- It is generally defined as the sudden increase of the voltage, at the power frequency, outside the normal tolerances value with duration of more than 1 cycle, and typically which less than 1 minute. Mainlyreferred to as 'over voltage', if continues for a certain period of time range.

\section{- Causes:}

1) Start and stop of heavy loads.

2) Poorly regulated transformers

\section{- Consequences:}

1) Flickering of lighting and screens.

2) Damage of sensitive equipment's.

\subsubsection{Harmonic Distortion (HD)}

Harmonic distortion is an issue of Power quality which is caused when harmonic currents produced by the nonlinear loads that are sent back to the supply system which interact adversely resulting additional losses in the wide range of power system equipment's [14].
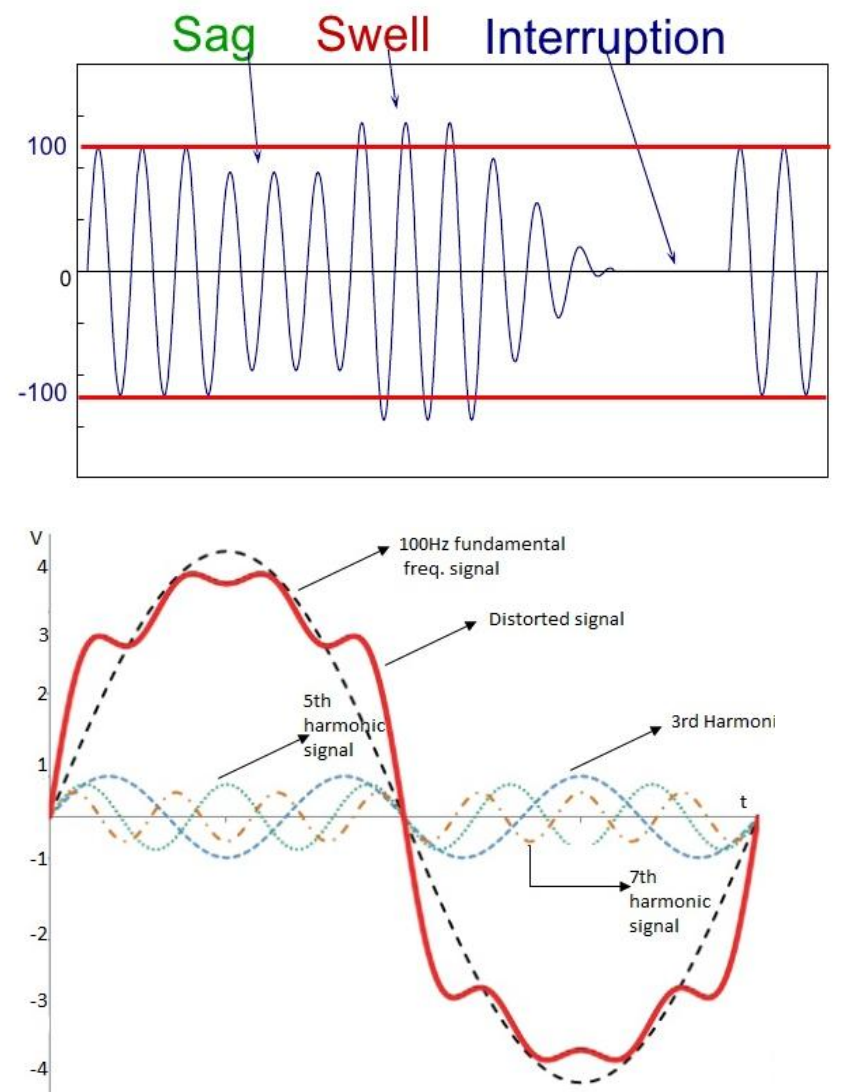

\subsection{Power Quality Monitoring}

Power quality monitoring is generally defined as the process of gathering, analysing, and interpreting raw measurement data into useful information which can be necessarily calculated. The strategy for social affair information is regularly managed by nonstop estimation of voltage and current throughout a high time. The strategy for study and usage has been performed physically, however ongoing advances in sign handling and AI fields have made it conceivable to style and execute insightful frameworks to consequently investigate and decipher information into helpful data with the fewest interferences.

Power quality monitoring projects are fundamentally accomplished for improving the framework wide power quality execution. Numerous modern and business clients have hardware that is touchy to control aggravations, and, along these lines, it's more imperative to comprehend the norm of intensity being given. Tests of these offices incorporate PC systems administration and media transmissionoffices, semiconductor and hardware fabricating offices, biotechnology and drug labs, and monetary information preparing focuses. Since the most recent decade, numerous organizations have actualized broad power quality checking [7] [9].

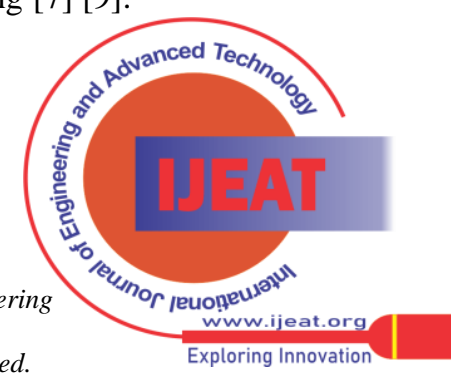


This is the first broad and main necessity. An impact maker may locate this target significant on the off chance that it has the need to know its framework execution, at that point coordinate that framework execution with the requirements of customers. Framework portrayal might be a proactive way to deal with power quality checking. By understanding the conventional force quality execution of a framework, a supplier can rapidly distinguish issues and may offer data to its clients to help them coordinate their touchy hardware's attributes with practical force quality qualities. This is regularly a responsive method of intensity quality observing, however it oftentimes distinguishes the clarification for hardware in congruence, which is that the activity to an answer [11].

Many power makers are presently thinking about extra administrations to supply clients. One of these administrations is supply separated degrees of intensity quality to coordinate the prerequisites of explicit clients. In one or the other case, observing gets basic to decide the nature of the power by a modified route in a frame [14] [17].

\subsubsection{Different Types of PQ Monitor}

Economically accessible screens of the Power Quality Monitoring System (PQM) are arranged into the accompanying.

\section{1) Portable Monitors}

- $\quad$ Used for investigating after an occasion has occurred which is partitioned into the accompanying:

\section{1) Voltage Recorders}

- The Recorders basically digitize voltage and current signs by taking examples of voltage and current over the long haul. Generally it is utilized for consistent checking of consistent state voltage varieties. Most significant factors to consider when choosing and utilizing a voltage recorder is figuring the RMS estimation of the specific estimated signal.

2)

\section{Disturbance Analyser}

- $\quad \square$ Designed to catch occasions in the wake of influencing touchy gadgets.

\section{2) Permanent Monitors:}

-These screens are for all time introduced full framework screens, deliberately positioned all through the office, telling the clients any force quality aggravation when it occurred.

- Characterize the full scope of power quality varieties.

- It records both the set off and tested information.

- The essential setting off relies upon RMS edges for RMS varieties and on wave shape for transient variety.

- 'Ongoing observing framework' is one of the case of one of this lasting checking framework.

\section{3) Real Time Monitoring System}

Real Monitoring System contains programming and correspondence workplaces for data collection, dealing with and result presentation. The item keeps up an informational collection of system execution information which can be gotten to. At the heart we have a PC improved for data base organization and examination. Both the disrupting impact analysers and voltage recorders can be composed into the constant noticing structure.

This lasting observing framework has the accompanying segments:-

\section{1) Measurement instruments}

-Involves both the voltage recorder and unsettling influence analyser.

- It has a trigger circuit to recognize occasions.

-Includes an information obtaining board to procure all the set off and inspected information.

\section{2) Monitoring workstation}

- It is utilized to assemble all data from the estimating instruments.

- Periodically send data to a control workstation.

\section{3) Control workstation}

-This station designs the boundaries of estimating instruments.

- Gathers and stores the information coming from the distant checking workstations.

- Does the information investigation and fare those data's.

\section{4) Control programming}

-This product drives the control workstation.

-Does the investigation and preparing of information data.

- Algorithms utilized for preparing differs as indicated by the framework utilized.

-Algorithms utilized might be founded on wavelet changes or master frameworks or some other progressed procedure.

\section{5) Database worker}

- Database the executive's framework ought to give quick admittance to numerous clients with no sort of execution disappointment.

- Also, it ought to evade any type of unapproved access.

\section{6) Communication channels}

- Selection of correspondence channel emphatically relies upon observing of the variety in the force quality.

\subsection{Power Quality Measurement}

There are certain parameters which are going to be measured in this paper:-

a) Rms Voltage and Current

b) Total Harmonic Distortion

c) Real Power

d) Apparent Power

e) Peak Values of Voltage and Current

\subsubsection{Objectives of this Paper}

The main objectives of this work are as follows:

1. To grow less effort of power quality measuring hardware/technology

2. To create programming based (NI LabVIEW) power quality estimation system so that the expense of gadgets might be less ordinarily and more proficient strategy might get produced.

3. To find out the peak and rms values of voltage and current along with the apparent, active and reactive power along with the error and accuracies and comparison with the ideal values.
Blue Eyes Intelligence Engineering and Sciences Publication (C) Copyright: All rights reserved.

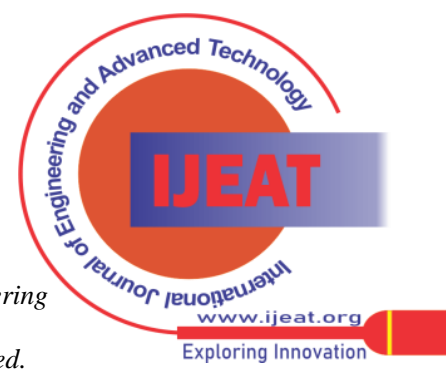




\subsection{Tools and Software Used}

\section{a) Labview}

LabVIEW (short for Laboratory Virtual Instrument Engineering Workbench)is generally defined as a framework plan stage and advancement climate for a visual programming language from National Instruments. LabVIEW is an exceptionally beneficial working environment for making custom applications that cooperate with genuine information or signs in fields, for example, science and designing. The net after effect of utilizinan apparatus, for example, LabVIEW is that higher quality ventures can be finished in less time with few individuals involved [9] [10].

\section{b) Data Acquisition Card (DAQ)}

Data acquisition (DAQ) is the process of measuring an event in terms of voltage, current, pressure, temperature or sound. A DAQ system includes high-speed data acquisition measurement hardware (a DAQ card or module), input devices such as sensors, and a computer or processor. Personal computer-based DAQ systems use the display, processing power, and connectivity of modern computers to provide a flexible, powerful and especially cost-effective measurement solution [10].

\subsection{Methods Used}

The initial step to fixing an issue is to quantify it. Renewables, module vehicles, inverters, on-framework stockpiling, HVDC, and different changes occurring on utility matrices sway power quality in manners not foreseen when the past age of instrumentation was planned. Force quality estimation gadgets based on NI innovation offer the quality and adaptability expected to help power frameworks engineers evaluate power quality issues that would somehow be hard to recognize.

- $\quad$ First step is LABVIEW 7.1 or 13.0 programming (any of the one) is utilized for building up the Power quality screen.

- Secondly, a tab control is made which for the most part saves space in the front board.

- DAQ (Data Acquisition Card) is utilized to procure and create signals (tests) to computerized numeric qualities which can be controlled by the PC and furthermore it is utilized for the constant checking framework.

- Numeric Controls are utilized various qualities and they are taken care of through numeric controls, for example, (voltage and current frequencies and adequacy).

- The rms values are shown by the marker which is named as voltage, current and power and furthermore the genuine and the clear force is determined.

- Transducers (Current and Voltage Transformers) is utilized for the estimations of rms and pinnacle estimations of voltage and current.

- Lastly the values of the voltage and current rms is found out and active/reactive and apparent power and energy along with power factor is calculated and the graph is found for the same. Also, comparison of the data i.e. actual calculated data and ideal data is compared and graph is found out.

\section{FLOW CHART OF THE SYSTEM}

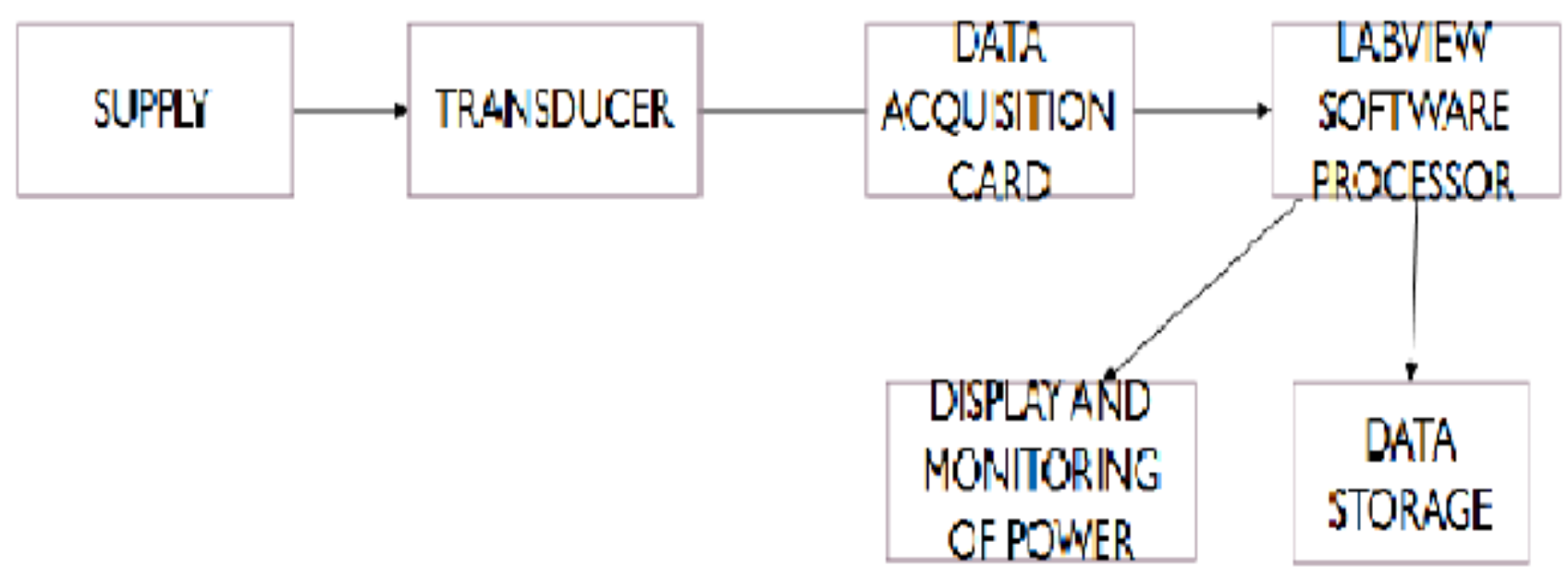

Transducer - Current Transformer and Voltage Transformer

\section{Software Developed for Power Quality Monitoring}

The main software for the system is quite simple and is basically divided into the main three parts: The first and foremost part is the creation of the graph and finding the rms values of voltage and current in which the
CT \& VT are used as transducers. The graph of the voltage and current is generally found out. In the block diagram a waveform chart is connected to find out the waveform of voltage and current with the DAQ and a time is set along with a loop which is while loop and the time is maintained accordingly.

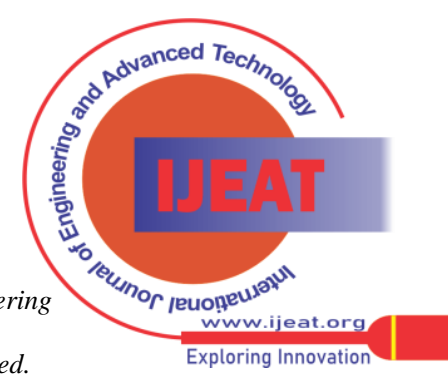




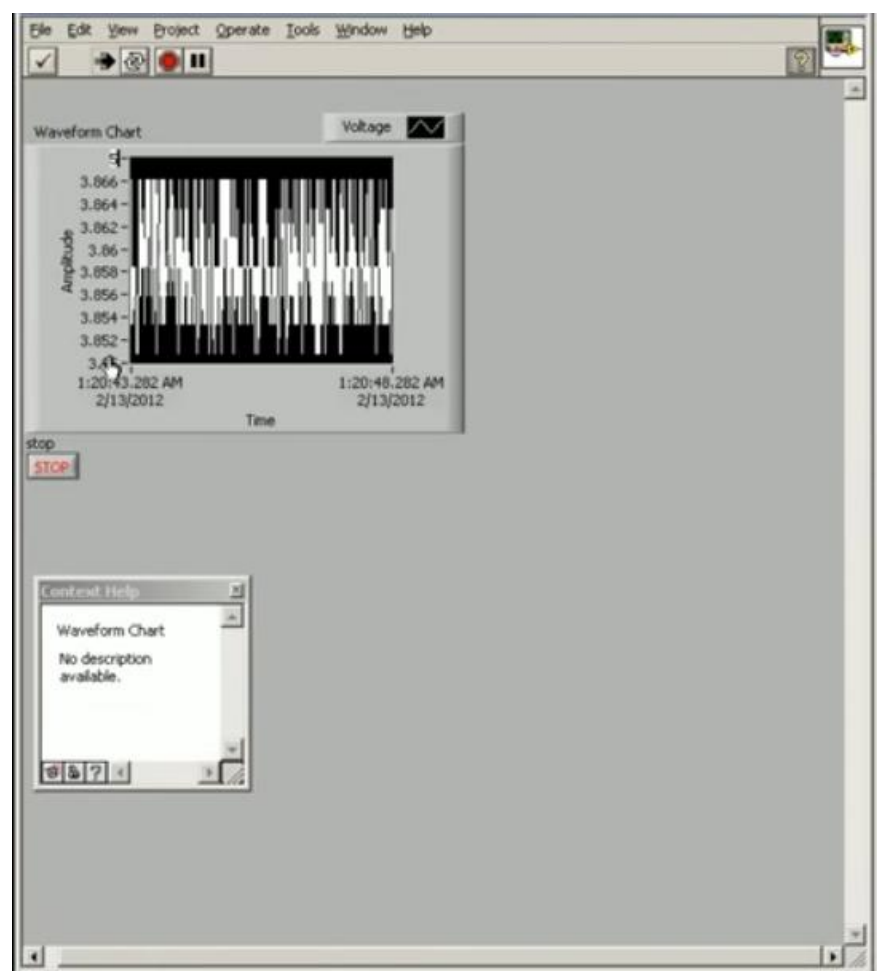

The second step is to find out the power quality measurement for that reason active power, reactive power and the apparent power is to be calculated on LabVIEW. The basic step for obtaining this value in the block diagram we have to create three numeric controls for voltage value, current values and power factor. The output is placed with numeric indicators which are named as active, apparent and reactive power. A formula bar is

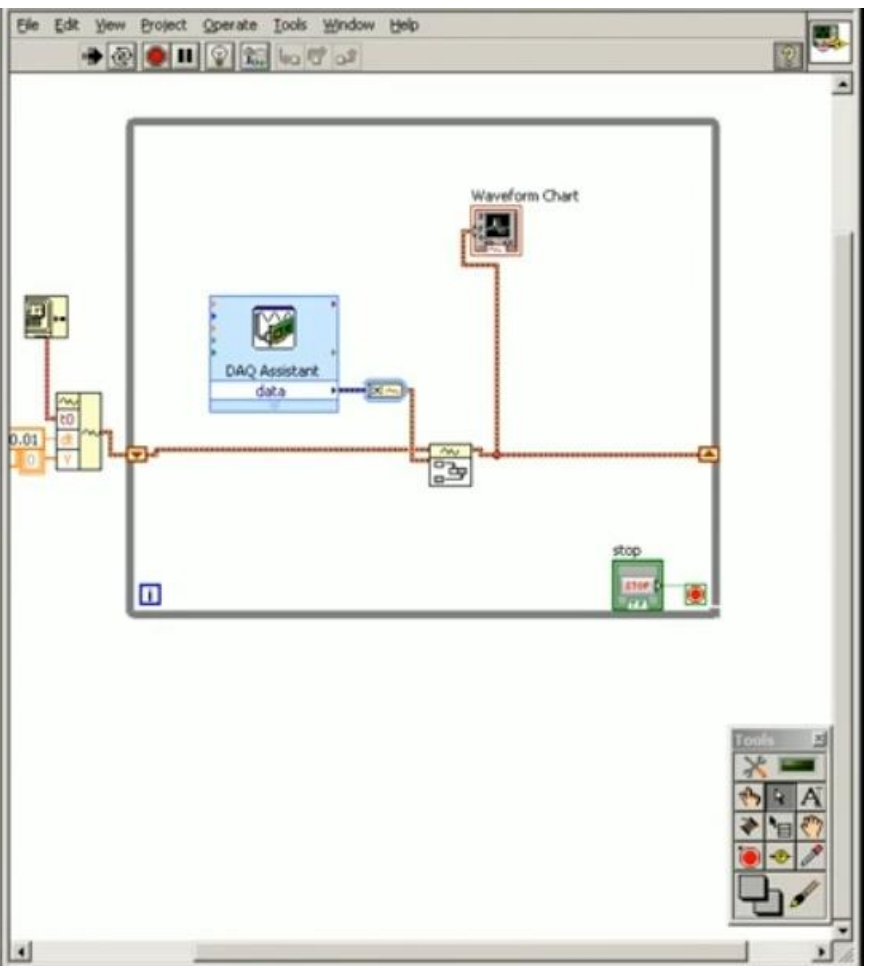

created and is connected with the power factor. The formula bar is created with right click on the express bar then arithmetic then formula. The formula for the power factor is added. So that direct values can be found out, then we are choosing random value of voltage and current and the value of the power factor should lie in between 0 and 1.

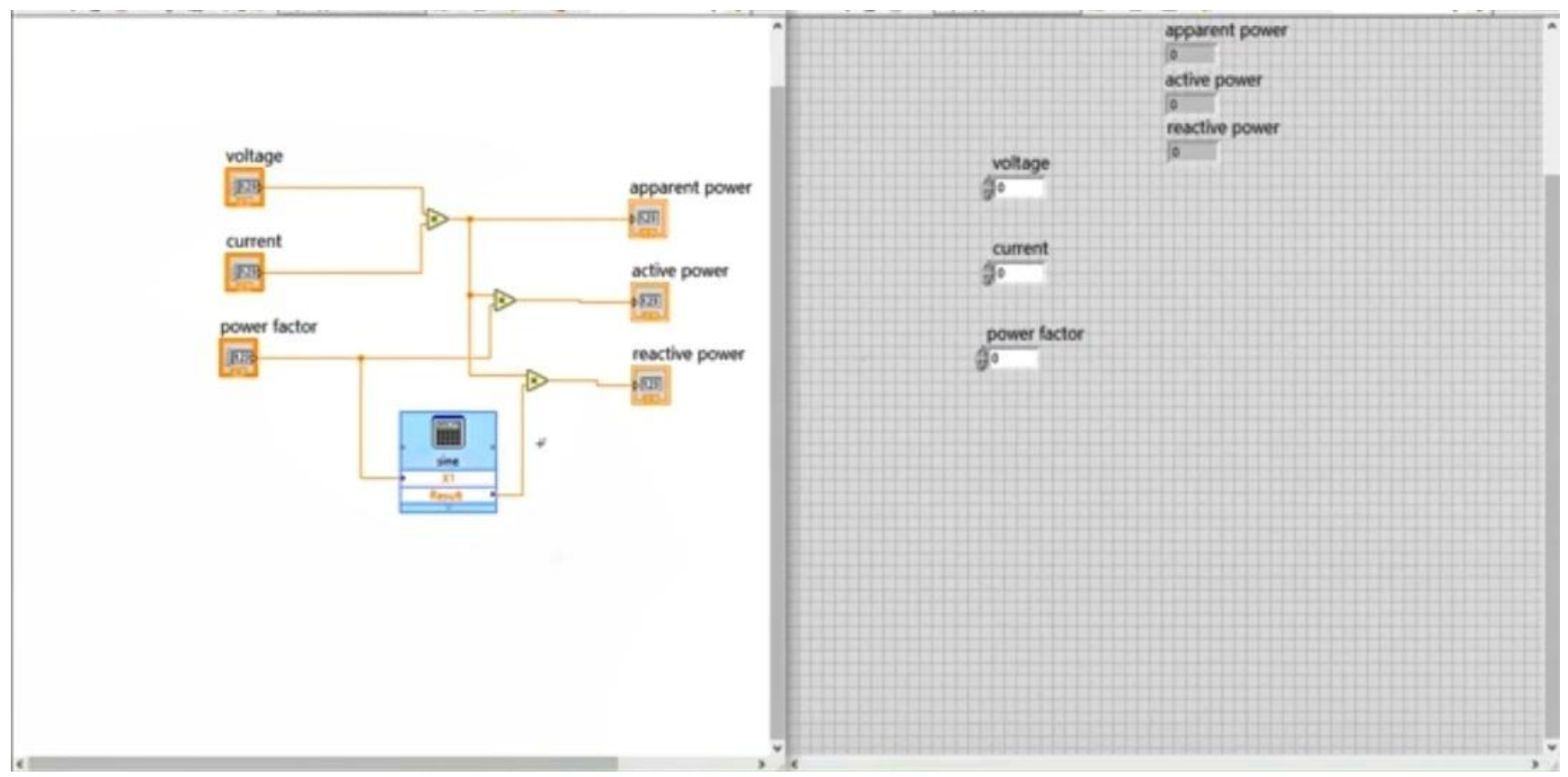

Lastly in this step the active, apparent and reactive energy is being found out which is almost same as the previous step only difference is that here whole value of the power is divided by time to get the energy. Only difference is that a time signal of 10 sec is generated. The basic step for obtaining this value in the block diagram we have to create three numeric controls for voltage value, current values and power factor. The output is placed with numeric indicators which is named as active, apparent and reactive energy. A formula bar is created and is connected with the power factor.

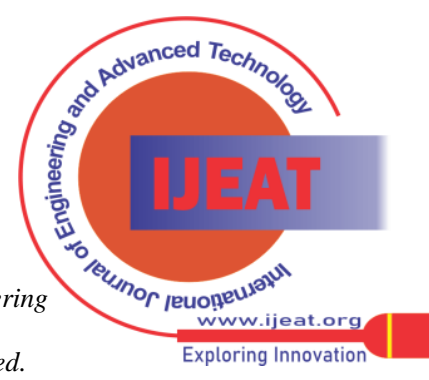


The formula bar is created with right click on the express bar then arithmetic then formula. The formula for the power factor is added. So that direct values can be found out, then we are choosing random value of voltage and current and the value of the power factor should lie in between 0 and 1.

Results Obtained

Table 1- Values of Active Power, Apparent Power \& Reactive Power

\begin{tabular}{|l|l|l|l|l|l|l|}
\hline $\begin{array}{c}\text { Serial } \\
\text { no. }\end{array}$ & Voltage (v) & Current (i) & $\begin{array}{c}\text { Power } \\
\text { factor }\end{array}$ & $\begin{array}{c}\text { Active } \\
\text { power }\end{array}$ & $\begin{array}{c}\text { Apparent } \\
\text { power }\end{array}$ & $\begin{array}{c}\text { Reactive } \\
\text { power }\end{array}$ \\
\hline 1 & 10 & 0.5 & 0.5774 & 5 & 8.6603 & 7.0711 \\
\hline 2 & 20 & 1 & 0.5774 & 20 & 34.641 & 28.284 \\
\hline 3 & 30 & 1.5 & 0.5774 & 45 & 77.942 & 63.34 \\
\hline 4 & 40 & 2 & 0.5774 & 80 & 138.56 & 113.18 \\
\hline 5 & 50 & 2.5 & 0.5774 & 125 & 216.51 & 176.78 \\
\hline 6 & 60 & 3 & 0.5774 & 180 & 311.77 & 254.56 \\
\hline 7 & 70 & 3.5 & 0.5774 & 245 & 424.35 & 346.48 \\
\hline 8 & 80 & 4 & 0.5774 & 320 & 554.26 & 452.55 \\
\hline 9 & 90 & 4.5 & 0.5774 & 405 & 701.48 & 572.76 \\
\hline 10 & 100 & 5 & 0.5774 & 500 & 866.03 & 707.11 \\
\hline
\end{tabular}

Table 2- Values of Active, Apparent and Reactive Energy

\begin{tabular}{|l|l|l|l|l|l|l|}
\hline $\begin{array}{c}\text { Serial } \\
\text { no. }\end{array}$ & $\begin{array}{c}\text { Voltage } \\
(\mathrm{v})\end{array}$ & Current (i) & $\begin{array}{c}\text { Power } \\
\text { factor }\end{array}$ & $\begin{array}{c}\text { Active } \\
\text { energy }\end{array}$ & $\begin{array}{c}\text { Apparent } \\
\text { energy }\end{array}$ & $\begin{array}{c}\text { Reactive } \\
\text { energy }\end{array}$ \\
\hline & & & & & & \\
\hline 1 & 10 & 0.05 & 0.05547 & 0.5 & 0.86603 & 0.70711 \\
\hline 2 & 20 & 0.1 & 0.05547 & 0.2 & 3.4641 & 2.8284 \\
\hline 3 & 30 & 0.15 & 0.05547 & 4.5 & 7.7942 & 6.334 \\
\hline 4 & 40 & 0.2 & 0.05547 & 8 & 13.856 & 11.31 \\
\hline 5 & 50 & 0.25 & 0.05547 & 12.5 & 21.651 & 17.67 \\
\hline 6 & 60 & 0.3 & 0.05547 & 18 & 31.177 & 25.45 \\
\hline 7 & 70 & 0.35 & 0.05547 & 24.5 & 42.435 & 34.64 \\
\hline 8 & 80 & 0.4 & 0.05547 & 32 & 55.426 & 45.255 \\
\hline 9 & 90 & 0.45 & 0.05547 & 40.5 & 70.148 & 57.276 \\
\hline 10 & 100 & 0.5 & 0.05547 & 50 & 86.603 & 70.7 \\
\hline
\end{tabular}

Graphs found of Voltage and Current against Power (Active, Apparent and Reactive)
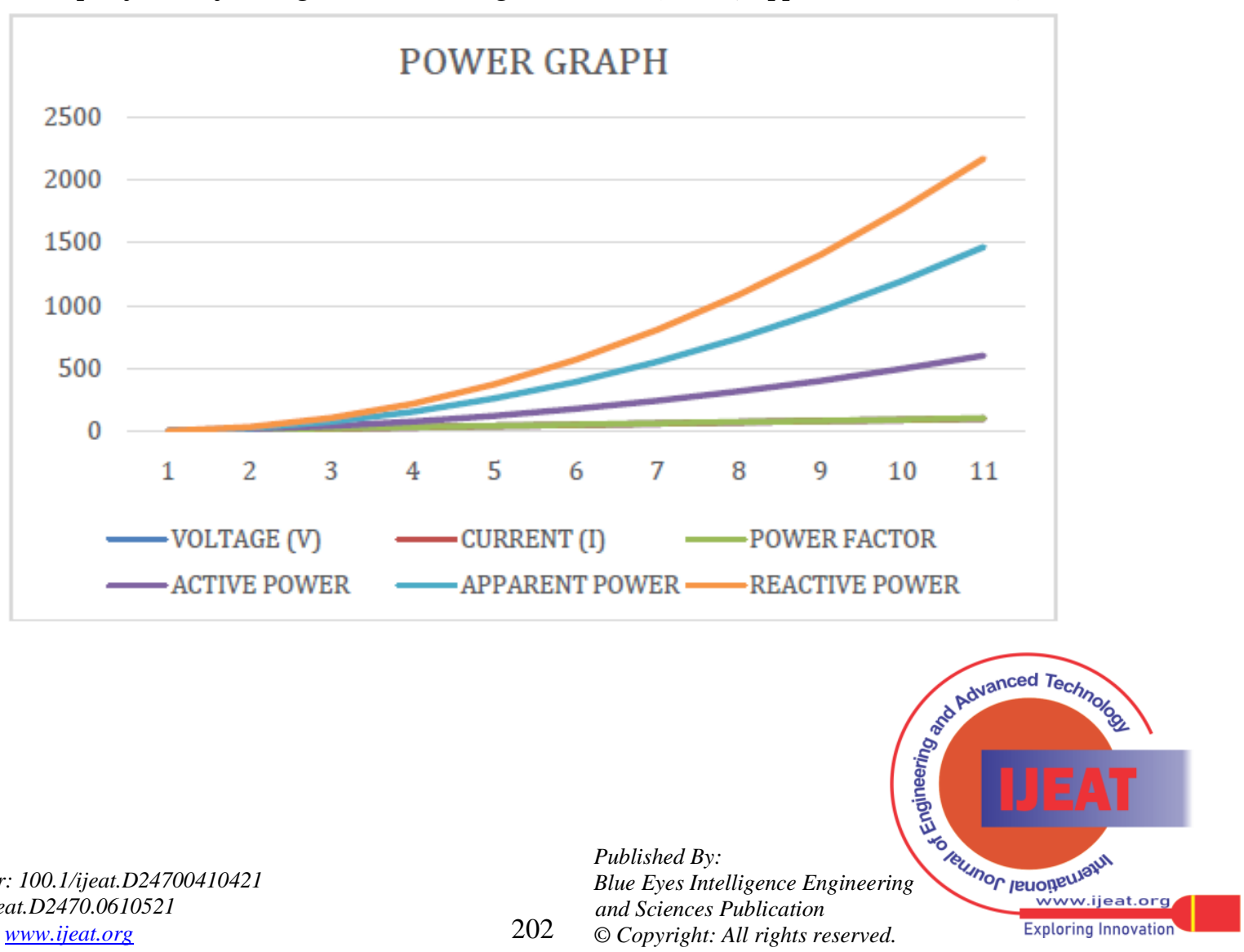


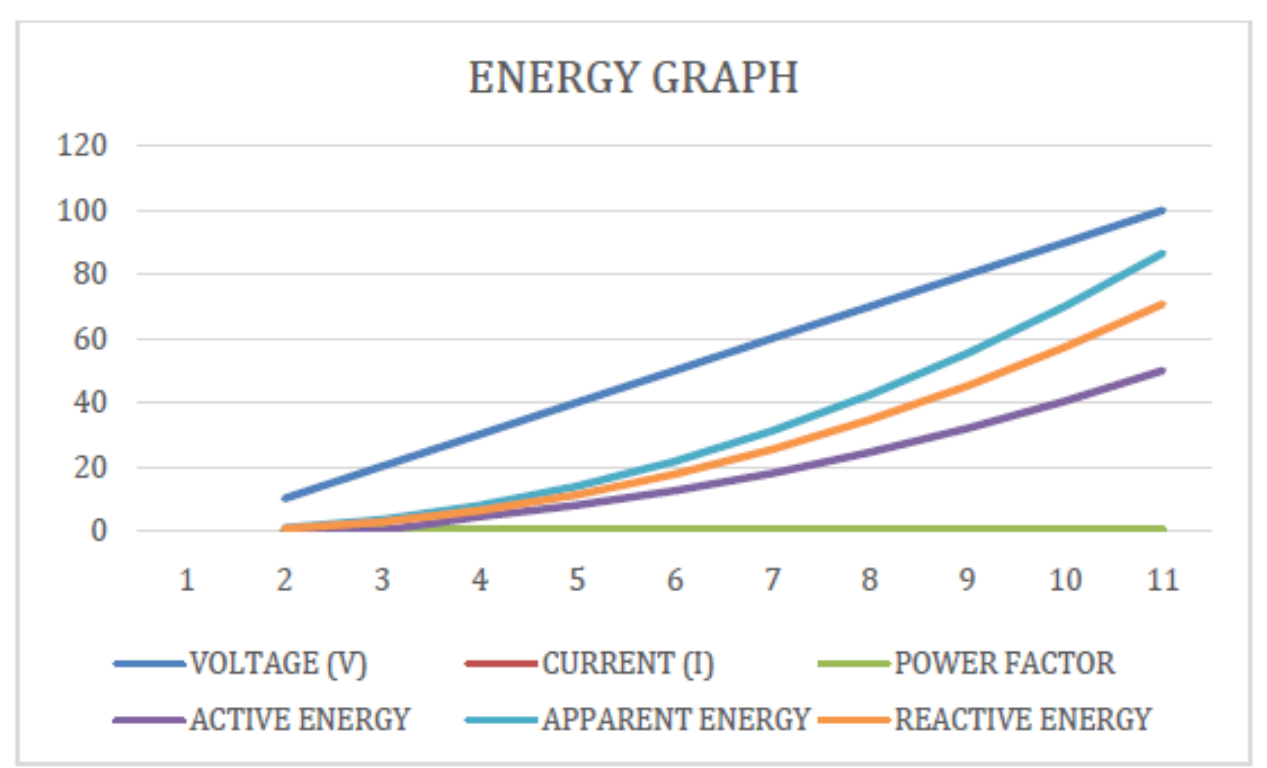

Table 3- Comparison of Calculated Data with Fluke instruments Data

\begin{tabular}{|c|c|c|c|c|c|}
\hline & $\begin{array}{l}\text { FLUKE } \\
\text { DATA }\end{array}$ & $\begin{array}{l}\text { CALCULATED } \\
\text { DATA }\end{array}$ & & & \\
\hline $\mathrm{V}(\mathrm{RMS})$ & 245.1 & 267.59 & & & \\
\hline I(RMS) & 175.53 & 193.339 & & & \\
\hline & & & & & \\
\hline & & & & & \\
\hline & & & & & \\
\hline & & & & & \\
\hline ACTIVE POWER (W) & 8.7 & 9.65 & ACTIVE ENERGY & 0.79 & 0.91 \\
\hline $\begin{array}{l}\text { REACTIVE POWER } \\
\text { (VAR) }\end{array}$ & 35.2 & 40.1 & $\begin{array}{l}\text { REACTIVE } \\
\text { ENERGY }\end{array}$ & 0.2 & 0.29 \\
\hline $\begin{array}{l}\text { APPARENT POWER } \\
\text { (VA) }\end{array}$ & 36.3 & 41.39 & $\begin{array}{l}\text { APPARENT } \\
\text { ENERGY }\end{array}$ & 0.2 & 0.17 \\
\hline & & & & & \\
\hline POWER FACTOR & 0.23966 & 0.233148 & & & \\
\hline & & & & & \\
\hline & ERROR (\%) & ACCURACY (\%) & & ERROR (\%) & $\begin{array}{l}\text { ACCURACY } \\
(\%)\end{array}$ \\
\hline & 0.95 & 99.05 & & 0.12 & 99.88 \\
\hline & 4.9 & 95.1 & & 0.09 & 99.91 \\
\hline & 5.09 & 94.91 & & 0.03 & 99.97 \\
\hline
\end{tabular}

Well after getting those readings we have founded the nature of the graph with Voltage and Current against Active, apparent and reactive power and observed that the nature of the graph tends on increasing with time and only the power factor remained in a constant state. The voltage and current values is taken in an increasing manner.

While from the second graph that is the energy graph we can conclude that while the power factor does remains in a steady constant state the energies (active, apparent and reactive) increases with the time and voltage is increasing linearly with the ongoing time. Lastly, comparison of data is done with the ideal values of fluke instruments and subsequently the error and accuracy of the calculated data with that of the ideal data.

\section{INFERENCES DRAWN FROM RESULTS}

After going through a lot of papers and reviews and getting the desired results, we get the following conclusions:-

* Power quality estimation is critical, furthermore it is exceptionally hard to screen it appropriately round the clock.

Published By:

Blue Eyes Intelligence Engineering

and Sciences Publication

(C) Copyright: All rights reserved.

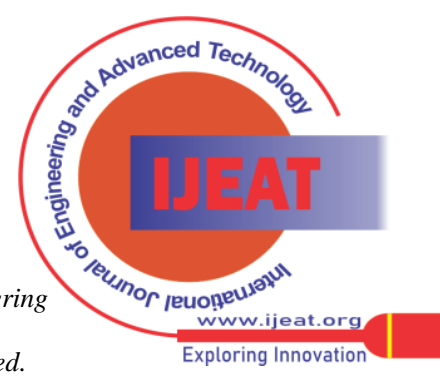



estimation are exorbitant.

* Lots of sounds, clamours and different unsettling influences are continuously creating because of various loads and power gadgets.

* Low power quality diminishes the life of items, breaking down of gadgets and more power utilization.

* LABVIEW is used here in this paper which is very much flexible and convenient software and through it distortion level and other variations in voltage and current are easily figured out.

* Power quality improvement is extremely perplexing procedure.

* Power quality estimation and control is intense issue in homes and also in commercial enterprises.

* Surveying different methods of literature divulges one thing that power quality estimation through hardware and remote testing requires lots of effort.

* Different methods and techniques are there for power monitoring such as digital filtering or Kalman filtering which basically focuses on the mathematical modelling that depicts the detection of transient waveforms.

* After getting those readings we have founded the nature of the graph with Voltage and Current against Active, apparent and reactive power and observed that the nature of the graph tends on increasing with time and only the power factor remained in a constant state. The voltage and current values is taken according to increasing manner.

* While from the second graph that is the energy graph we can conclude that while the power factor does remains in a steady constant state the energies (active, apparent and reactive) increases with the time and voltage is increasing linearly with the ongoing time.

\section{CONCLUSION AND FUTURE SCOPES}

Dependability and consistency of power supply are a standout amongst the most imperative conditions for the exercises of modern and administration organizations. Issues beginning from poor Power Quality incorporate intrusions, symphonious contamination and so on. In this way the heaps associated with a system with such issues will fizzle, have a short lifetime and the productivity of the framework will diminish.

Observing the Power Quality will make conceivably to distinguish the sources/reasons for issues inside the end client's system. The arrangement would be either expelling the source or making insusceptible the establishment from the poor power quality. Both arrangements typically cost far not exactly the potential harms that may infer. For that reason monitoring is done using LABVIEW Software and the values of active reactive and the apparent power is generally found out.

Penetration of grid associated sustainable power frameworks and shrewd burdens dependent on force gadgets innovation has been expanding in low and medium voltage circulation. Power Electronics framework is a critical innovation for dissemination networks which can move electrical force from environmentally friendly power sources to grid or produce managed recurrence and
* The types of equipment utilized for power quality

additionally voltage for various loads, for example, factor speed drives and battery chargers.

New requests and demands are for

a) Cost and size decrease,

b) Execution and quality improvement

c) Adaptability on force the executives have advanced force hardware applications broadly in mechanical, business and private areas, for example, in transportation, utility and home apparatuses every year.

\section{REFERENCES}

1. Penghui Li, LijieZhao ; Haijun Bai ; Yanhua Zhang; 2010 "Power Quality Monitoring Based on Spectrum Analysis published on IEEE Conference on E-Product

2. Fadhel Khalifa; Khaled Jelassi, “An Energy and Power Monitoring System of Power Distribution,2016 2016 International Conference on Electrical Sciences and Technologies in Maghreb (CISTEM)

3. Zimmer; Sezi and J.Lang 2005,"Power Quality Monitoring and Analysis System", IEEE Conference Paper Xploree

4. Phang Yoke Yin; M. V. Chilukur i2009;"Remote Power Quality Monitoring System using LABVIEW", IEEE Paper Published in 2009

5. Dr. Puneet Pahuja, Ravi, Prateek Chandra and Savita "Power Quality Testing and Measurement through LABVIEW", 2015; IJEECE CONFERENCE

6. Yogesh V. Mangalekar; R. T. Ugale, 2015; IEEE XPLOREE CONFERENCE PAPER

7. P.P. Barker ; J.J. Burke ; R.T. Mancao ; T.A. Short ; C.A. Warren ; C.W. Burns ; J.J. Siewierski;1994; IEEE TRANSACTION ON POWER ENERGY SEMINAR

8. Vaclav Matz; Tomas Radil; Pedro Ramos; A. Cruz Serra; 2007 IEEE INSTRUMENTATION CONFERENCE

9. Z. Kokolanski, M. Srbinovska, A. Simevski, C. Gavrovski and V. Dimcev; 2009 ELECTRONICS, VOL. 13, NO. 1, JUNE 2009

10. Vinay Dwivedi; Dheerendra Singh; 2010 IEEE SPEEDRAM CONFERENCE

11. Shahedul HAQUE Laskar, Muhammad MohibullahJanuary 2011 Conference: Universities' Power Engineering Conference (UPEC), Proceedings of 2011 46th International

12. Wang Shenghui, Chao Yong Jin Xing The 2nd International Conference on Computer Application and System Modeling (2012)

13. Neilson Jones, K. Chakraborty (2011) "Power Quality of Grid using LABVIEW"; IEEE TRANSACTION ON POWER ENERGY SEMINAR

14. Preethi Loganayaki.V, 2 Keerthiga.S.,3 Sundar Raj.S, "An on-line distributed power quality monitoring system based on internet and LabVIEW", International Journal of Scientific \& Engineering Research, Volume 4, Issue 5, May-2013

15. Alsayyed, Basel \&ElSheikh, Hoda\&Fadoun, Abbas. (2015). Review of power quality monitoring systems. IEOM 2015 - 5th International Conference on Industrial Engineering and Operations Management, Proceeding. 10.1109/IEOM.2015.7093825.

16. Dr.D.Sivakumar, J.P.Srividhya, and T.Shanmathi, "A Review on Power Quality Monitoring and Its Controlling Techniques" 8th International Conference on Latest Trends in Engineering and Technology (ICLTET'2016) May 5-6 2016 Dubai (UAE)

17. David Guillot "POWER QUALITY MONITORING" ALSTOM Transmission \& Distribution, Protection \&Contrôle (2019)

18. A. Prudenzi, M. Di Lillo, A. Silvestri, M.C.Falvo "Software Tool for Energy Audit Activities in Building" IEEE International Symposium on Power Electronics, Electrical Drives, Automation and Motion, August 6, 2008.

19. Azimah Omar, Norman, Marium, Mohd Amran MohdRadzi, "Software development for energauditingpractice" IEEE, SCORED 2003 Proceedings, Putrajaya, Malaysia, March 4, 2003.

20. Bucci, G, "Embedded power and energy measurement system based on an analog multiplier Instrumentation and Measurement, IEEE Transactions on (Vol. 62 , Issue: 8 ), pp: 2248 - 225August, 2013.

21. De Yong, D, "Educational software for power quality analysis", Latin America Transactions, IEE (Revista IEEE America Latina) (Volume: 11, Issue: 1), pp: 479 - 485, February, 2013.

\section{Published By:}

Blue Eyes Intelligence Engineering

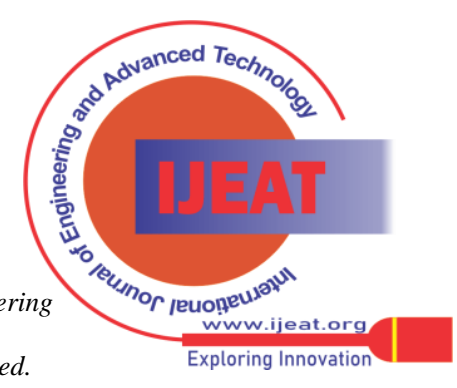


22. Feng Yuan, Qian Ai; Xing $\mathrm{He}$, "Research on dynamic load modelling based on Power quality monitoring system", Generation, Transmission \& Distribution, IET

Vol.7, Issue: 1, pp: 46 - 51, January, 2013.

23. Ren, Stefan Giurgea, "A hybrid method for power system frequency estimation", Power Deliver IEEE Transactions on (Vol. 27, Issue: 3), pp: 1252 - 1259, July 2012.

\section{AUTHORS PROFILE}

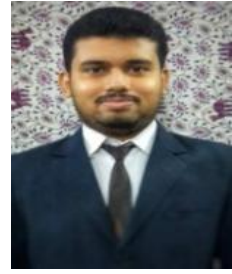

Abhishek Sur, completed his B.tech in Instrumentation and Control Engineering in 2018 from West Bengal University of Technology and currently completed his M.Tech in Power System (Major) from Sharda University in 2021. Currently, he is a Power Quality Research Assistant.

His interest involves:

\section{- Control Theory}

- Industrial Instrumentation

- Process Control

- Optimization Techniques

- Modeling and Analysis of Power Systems

- Extra-High Voltage Transmission

- Virtual Instrumentation

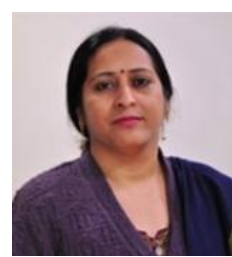

Suman Lata Dhar, completed B.E in Instrumentation from the university of Mumbai in 2000 and M.Tech in Electrical and Electronics from GBTU, Lucknow. She has been awarded 'Vishisth Shishak Samman for excellence in teaching for the year 2007-2008 by the Sharda Group of Institutions (SGI).Her areas of interest are Signal Processing ,Wireless Sensor Networks and Virtual Instrumentation.

\section{Experience}

- 14 years

\section{Qualification}

- Pursuing Ph.D

- M.Tech

\section{Award \& Recognition}

- Awarded 'VishisthShikshak Samman for excellence in teaching for the year 2007-2008 by the Sharda Group of Institutions (SGI).

\section{Research}

- Efficient Method for Improving the Performance of CIC Decimation Filters", S.N.Shran, Shaheen Naz \&Suman Lata, Trends in Software and Networking Technology (ETSNT09), 17-18 April 2009, Amity University U.P.

- $\quad$ "Use of Smoothing and Magnitude and Phase Estimation in Spectral Subtraction" Krishna Raj ,Suman Lata \&ShaheenNaz,Advanced Communication Technologies and Applications (NCACA 2009) 1314 May,2009, Gitanjali Institute of Technical Studies, Udaipur,Rajasthan

- "Noise Reduction using Wiener Filtering for Speech Signals" Suman Lata ,Shaheen Naz \& Krishan Raj ,Trends in Instrumentation and Control Engineering (TICE-09),29-30 October , Thapar University Patiala, Punjab

- "Noise Reduction in Fetal ECG using Wavelets", A.H.Siddique, Suman Lata and Shiwani Saini, Satellite Conference ICM2010 on Mathematics in science and Technology, 15-17 August 2010, Indian Habitat Center, Lodhi Road, New Delhi

- "Fast Processing Using Signed Digit Number System", Krishna Raj \& Suman Lata published international Journal of Electronics Engineering serials publication

\section{Certifications}

- High Impact Teaching Skills and Mission 10X learning Approach.

\section{Area of Interest}

- Wireless Sensor Networks, Digital Signal Processing

- Virtual Instrumentation

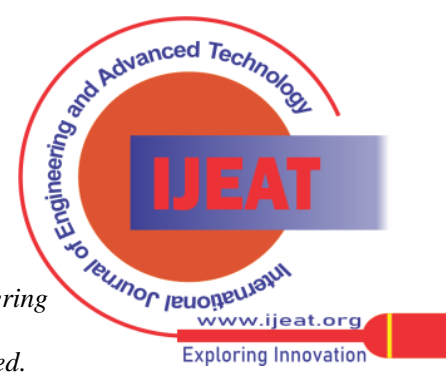

